\title{
Convergence and stability theorems for the Picard-Mann hybrid iterative scheme for a general class of contractive-like operators
}

\author{
Hudson Akewe ${ }^{1}$ and Godwin Amechi Okeke $2^{2 *}$
}

\section{"Correspondence:}

gaokeke1@yahoo.co.uk

2Department of Mathematics,

Covenant University, Canaanland,

KM 10 Idiroko Road, P.M.B. 1023, Ota,

Ogun State, Nigeria

Full list of author information is

available at the end of the article

\begin{abstract}
In this paper we use the general class of contractive-like operators introduced by Bosede and Rhoades (J. Adv. Math. Stud. 3(2):1-3, 2010) to prove strong convergence and stability results for Picard-Mann hybrid iterative schemes considered in a real normed linear space. We establish the strong convergence and stability of the Picard iterative scheme as a corollary. Our results generalize and improve a multitude of results in the literature, including the recent results of Chidume (Fixed Point Theory Appl. 2014:233, 2014).
\end{abstract}

MSC: $47 \mathrm{H} 09 ; 47 \mathrm{H} 10 ; 54 \mathrm{H} 25$

Keywords: strong convergence result; Picard-Mann hybrid iterative schemes; contractive-like operators

\section{Introduction and preliminary definitions}

Fixed point iterative schemes are designed to be applied in solving equations arising in physical formulation but there is no systematic study of the numerical aspects of these iterative schemes. In computational mathematics, it is of vital interest to know which of the given iterative procedures converge faster to a desired solution, commonly known as the rate of convergence. Some of the notable authors whose research is in this direction are Hussain et al. [1], Phuengrattana and Suantai [2] and Khan [3]. Harder and Hicks [4, 5] revealed the importance of investigating the stability of various iteration procedures for various classes of nonlinear mappings. Harder [6] established applications of stability results to first-order differential equations.

We will now consider some of these schemes, as they are relevant to this work.

Let $(X, d)$ be a metric space and $T: X \rightarrow X$ be a selfmap of $X$. Define $F_{T}=\{p \in X: T p=p\}$ to be the set of fixed points of $T$. For $x_{0} \in X$, the sequence $\left\{x_{n}\right\}_{n=1}^{\infty}$ defined by

$$
x_{n+1}=T x_{n}, \quad n \geq 0,
$$

is called the Picard iterative scheme.

Let $(E,\|\cdot\|)$ be a real normed linear space and $T: E \rightarrow E$ be a selfmap of $E$. For $x_{0} \in E$, the sequence $\left\{x_{n}\right\}_{n=0}^{\infty}$, defined by

$$
x_{n+1}=\left(1-\alpha_{n}\right) x_{n}+\alpha_{n} T x_{n}, \quad n \geq 0,
$$

(c) 2015 Akewe and Okeke; licensee Springer. This article is distributed under the terms of the Creative Commons Attribution 4.0 International License (http://creativecommons.org/licenses/by/4.0/), which permits unrestricted use, distribution, and reproduction in any medium, provided you give appropriate credit to the original author(s) and the source, provide a link to the Creative Commons license, and indicate if changes were made. 
where $\left\{\alpha_{n}\right\}_{n=0}^{\infty}$, is a real sequence in $[0,1]$ such that $\sum_{n=0}^{\infty} \alpha_{n}=\infty$ is called the Mann iterative scheme [7].

If each $\alpha_{n}=1$ in (1.2), we have the Picard iterative scheme (1.1).

Rhoades [8], perhaps for the first time, used computer programs to compare the rate of convergence of Mann and Ishikawa iterative procedures. He illustrated the difference in the rate of convergence for increasing and decreasing functions through examples.

In [2], Phuengrattana and Suantai defined the SP iterative scheme and proved that this scheme is equivalent to, and faster than, Mann [9], Ishikawa and Noor iterative schemes for increasing functions. Recently, Chugh and Kumar [10] introduced the CR iterative scheme and proved some convergence results. In the light of the iterative schemes mentioned above, it is clear that the study of the rate of convergence of several iterative schemes has attracted the interest of several well-known mathematicians. Rhoades and Soltuz [11] introduced some multistep iterative schemes and proved some equivalence results. Akewe et al. [12] introduced the Kirk-multistep type iterative schemes and proved strong convergence and stability results, with some numerical examples to back up their work. These various results are worth emulating.

In 2013, Khan [3] gave a different perspective to iteration procedure. He introduced the following Picard-Mann hybrid iterative scheme for a single nonexpansive mapping $T$. For any initial point $x_{0} \in E$, the sequence $\left\{x_{n}\right\}_{n=0}^{\infty}$ is defined by

$$
\begin{aligned}
& x_{n+1}=T y_{n}, \\
& y_{n}=\left(1-\alpha_{n}\right) x_{n}+\alpha_{n} T x_{n}, \quad n \geq 0,
\end{aligned}
$$

where $\left\{\alpha_{n}\right\}_{n=0}^{\infty}$ is a real sequence in $[0,1]$.

He showed that the hybrid scheme (Picard-Mann scheme (1.3)) converges faster than all of Picard (1.1), Mann (1.2) and Ishikawa [13] iterative schemes in the sense of Berinde [14] for contractions. He also proved the strong convergence and weak convergence theorems with the help of his iterative process (1.3) for the class of nonexpansive mappings in general Banach spaces and applied it to obtain results in uniformly convex Banach spaces.

Motivated by the work of Khan [3], we prove the strong convergence of the Picard-Mann iterative scheme for a general class of operators in a real normed space.

Osilike [15] proved several stability results, which are generalizations and extensions of most of the results of Rhoades [16], using the following contractive definition: for each $x, y \in X$, there exist $a \in[0,1)$ and $L \geq 0$ such that

$$
d(T x, T y) \leq a d(x, y)+L d(x, T x)
$$

In 2003 Imoru and Olatinwo [17] proved some stability results using the following general contractive definition:

for each $x, y \in X$, there exist $\delta \in[0,1)$ and a monotone increasing function $\varphi: R^{+} \rightarrow R^{+}$with $\varphi(0)=0$ such that

$$
d(T x, T y) \leq \delta d(x, y)+\varphi(d(x, T x)) .
$$

In a recent paper Bosede and Rhoades [18] made an assumption implied by (1.4) and the one which renders all generalizations of the form (1.5) pointless. That is if $x=p$ (is a fixed 
point) then (1.4) becomes

$$
d(p, T y) \leq \delta d(p, y)
$$

for $\delta \in[0,1)$ and all $x, y \in X$.

In a real normed linear space setting, (1.6) is the same as

$$
\|p-T y\| \leq \delta\|p-y\|
$$

for $\delta \in[0,1)$ and all $x, y \in X$.

In 2014 Chidume and Olaleru [19] gave several examples to show that the class of mappings satisfying (1.7) is more general than that of (1.5) and (1.4), provided the fixed point exists. The authors [19] proved that every contraction map with a fixed point satisfies inequality (1.7) in the following example.

Several well-known mathematicians have established some interesting fixed points results for certain classes of nonlinear mappings (see, e.g. Bosede [20], Rhoades [21], Zamfirescu [22]).

Example 1.1 [19] Let $E=l_{\infty}, K=\left\{x \in l_{\infty}:\|x\| \leq 1\right\}$ and let

$$
T: K \rightarrow K
$$

be defined by

$$
T x=\frac{9}{10}\left(0, x_{1}^{2}, x_{2}^{2}, x_{3}^{2}, \ldots\right) \quad \text { for } x=\left(x_{1}, x_{2}, x_{3}, \ldots\right) \in K
$$

Then

(i) $T$ is continuous and maps $K$ into itself.

(ii) $T p=p$ implies $p=0$.

(iii)

$$
\begin{aligned}
\|T x-p\|_{\infty} & =\frac{9}{10}\left\|\left(0, x_{1}^{2}, x_{2}^{2}, x_{3}^{2}, \ldots\right)\right\|_{\infty} \\
& \leq \frac{9}{10}\left\|\left(0, x_{1}, x_{2}, x_{3}, \ldots\right)\right\|_{\infty} \\
& =\frac{9}{10}\|x-p\|_{\infty} \quad \forall x \in K(\text { since } p=0) .
\end{aligned}
$$

(iv) $T$ is not a contraction map. To see this, let $x=\left(\frac{3}{4}, \frac{3}{4}, \frac{3}{4}, \ldots\right)$ and $y=\left(\frac{1}{2}, \frac{1}{2}, \frac{1}{2}, \ldots\right)$.

Clearly, $x, y \in K,\|x-y\|_{\infty}=\frac{1}{4}$, and $\|T x-T y\|_{\infty}=\frac{45}{160}$.

Suppose there exists $a \in[0,1)$ such that $\|T x-T y\|_{\infty} \leq a\|x-y\|_{\infty}, \forall x, y \in K$, we must then have that

$$
\|T x-T y\|_{\infty}=\frac{45}{160} \leq \frac{a}{4}=\|x-y\|_{\infty}
$$

for the above choices of $x$ and $y$. But then this implies that $a \geq \frac{180}{160}>1$. So, $T$ is not a contraction map. 
(v) It is clear that every contraction map with a fixed point satisfies inequality (1.7).

This completes our example.

We now give the following example.

Example 1.2 Let $E=l_{\infty}, B:=\left\{x \in l_{\infty}:\|x\| \leq 1\right\}$ and let $T: E \rightarrow B \subseteq E$ be defined by $T x=\frac{11}{12}\left(0, x_{1}^{2}, x_{2}^{2}, x_{3}^{2}, \ldots\right)$ if $\|x\|_{\infty} \leq 1, T x=\frac{11}{12\|x\|_{\infty}^{2}}\left(0, x_{1}^{2}, x_{2}^{2}, x_{3}^{2}, \ldots\right)$ if $\|x\|_{\infty}>1$ for $x=$ $\left(x_{1}, x_{2}, x_{3}, \ldots\right) \in l_{\infty}$. Then $T p=p$ if and only if $p=0$. We compute as follows:

$$
\begin{aligned}
\|T x-p\|_{\infty} & =\frac{11}{12}\left\|\left(0, x_{1}^{2}, x_{2}^{2}, x_{3}^{2}, \ldots\right)\right\|_{\infty} \text { if }\|x\|_{\infty} \leq 1, \\
\|T x-p\|_{\infty} & =\frac{11}{12\|x\|_{\infty}^{2}}\left\|\left(0, x_{1}^{2}, x_{2}^{2}, x_{3}^{2}, \ldots\right)\right\|_{\infty} \text { if }\|x\|_{\infty}>1, \text { so that } \\
\|T x-p\|_{\infty} & =\frac{11}{12}\|x\|_{\infty}^{2} \leq \frac{11}{12}\|x\|_{\infty} \text { if }\|x\|_{\infty} \leq 1, \\
\|T x-p\|_{\infty} & =\frac{11}{12} .1 \text { if }\|x\|_{\infty}>1 .
\end{aligned}
$$

Hence, we obtain that $\|T x-p\|_{\infty}=\frac{11}{12}\|x-p\|_{\infty}$ for every $x \in l_{\infty}, p=0$.

Hence, $T$ satisfies contractive condition (1.7). But the map $T$ is not a contraction. To see this, take $x=\left(\frac{3}{4}, \frac{3}{4}, \frac{3}{4}, \ldots\right) ; y=\left(\frac{1}{2}, \frac{1}{2}, \frac{1}{2}, \ldots\right)$. Then $\|x-y\|_{\infty}=\frac{1}{4} ;\|T x-T y\|_{\infty}=$ $\frac{11}{12}\left\|\left(0, \frac{5}{16}, \frac{5}{16}, \ldots\right)\right\|_{\infty}=\frac{55}{192}$.

Suppose there exists $a \in[0,1)$ such that $\|T x-T y\|_{\infty} \leq a\|x-y\|_{\infty}$ for every $x, y \in E$, then we must have $\frac{55}{192} \leq \frac{a}{4}$, which yields that $a \geq \frac{220}{192}>1$, a contradiction. So, $T$ is not a contraction map.

Example 1.3 Let $E=[0,1]$. Define $T:[0,1] \rightarrow[0,1]$ by $T x=\frac{x}{2}$, where $[0,1]$ has the usual metric. Then $T$ satisfies inequality $(1.7)$ and $F(T)=[0,1]$.

We shall show that the Picard-Mann hybrid iterative scheme (1.3) is $T$-stable.

Now, let $p=0$. Take $\alpha_{n}=\frac{1}{2}, y_{n}=\frac{1}{n}$ for each $n \geq 1$.

Then $\lim _{n \rightarrow \infty} y_{n}=0$.

We see that

$$
\begin{aligned}
\epsilon_{n} & =\left|y_{n+1}-T y_{n}\right| \\
& =\left|y_{n+1}-\frac{y_{n}}{2}\right| \\
& =\left|y_{n+1}-\frac{1-\alpha_{n}}{2} y_{n}-\frac{\alpha_{n}}{2}\left(\frac{y_{n}}{2}\right)\right| \\
& =\left|\frac{1}{n+1}-\frac{1}{4 n}-\frac{1}{8 n}\right| .
\end{aligned}
$$

We have

$$
\lim _{n \rightarrow \infty} \epsilon_{n}=0
$$

Hence the Picard-Mann hybrid iterative scheme (1.3) is $T$-stable.

We shall need the following lemma in proving our result.

Lemma 1.1 [23] Let $\delta$ be a real number satisfying $0 \leq \delta<1$ and $\left\{\epsilon_{n}\right\}_{n=0}^{\infty}$ be a sequence of positive numbers such that $\lim _{n \rightarrow \infty} \epsilon_{n}=0$. Then, for any sequence of positive numbers $\left\{u_{n}\right\}_{n=0}^{\infty}$ satisfying $u_{n+1} \leq \delta u_{n}+\epsilon_{n}, n=0,1,2, \ldots$, we have $\lim _{n \rightarrow \infty} u_{n}=0$. 


\section{Main results}

Theorem 2.1 Let $(E,\|\cdot\|)$ be a real normed linear space and $T: E \rightarrow E$ be a map with a fixed point $p$ satisfying the condition

$$
\|T x-p\| \leq \delta\|x-p\|
$$

for each $x, y \in E, 0 \leq \delta<1$. For arbitrary $x_{1} \in E$, let $\left\{x_{n}\right\}_{n=0}^{\infty}$ be the Picard-Mann hybrid iterative scheme defined by (1.3), where $\left\{\alpha_{n}\right\}_{n=0}^{\infty}$ is a real sequence in $[0,1]$. Then $\left\{x_{n}\right\}_{n=0}^{\infty}$ converges strongly to $p$.

Proof In view of (2.1) and (1.3) we have

$$
\begin{aligned}
\left\|x_{n+1}-p\right\| & =\left\|T y_{n}-T p\right\| \\
& \leq \delta\left\|y_{n}-p\right\|,
\end{aligned}
$$

and

$$
\begin{aligned}
\left\|y_{n}-p\right\| & \leq\left(1-\alpha_{n}\right)\left\|x_{n}-p\right\|+\alpha_{n}\left\|T x_{n}-T p\right\| \\
& \leq\left(1-\alpha_{n}\right)\left\|x_{n}-p\right\|+\alpha_{n} \delta\left\|x_{n}-p\right\| .
\end{aligned}
$$

Substituting (2.3) in (2.2), we have

$$
\left\|x_{n+1}-p\right\| \leq \delta\left[1-\alpha_{n}(1-\delta)\right]\left\|x_{n}-p\right\| .
$$

Using the fact that $0 \leq \delta<1, \alpha_{n} \in[0,1)$ and $\sum_{n=0}^{\infty} \alpha_{n}=\infty$, we have from Lemma 1.1 that $\lim _{n \rightarrow \infty}\left\|x_{n+1}-p\right\|=0$; that is, $\left\{x_{n}\right\}_{n=0}^{\infty}$ converges strongly to $p$. This ends the proof.

Theorem 2.1 leads to the following corollary.

Corollary 2.2 (Chidume [7]) Let $(E,\|\cdot\|)$ be a real normed linear space and $T: E \rightarrow E$ be a map with a fixed point $p$ satisfying the contractive condition

$$
\|T x-p\| \leq \delta\|x-p\|
$$

for each $x, y \in E, 0 \leq \delta<1$. For an arbitrary $x_{1} \in E$, let $\left\{x_{n}\right\}_{n=0}^{\infty}$ be the Picard iterative scheme defined by (1.1). Then (1.1) converges strongly to $p$.

Remark 2.1 Theorem 2.1 generalizes several results in the literature by considering a larger class of contractive-type operators, including the results of Chidume [7].

\section{Stability results for the Picard-Mann iterative schemes in real normed spaces}

In this section we prove stability results for the Picard-Mann iterative schemes defined by (1.3) for a general class of contractive-like operators introduced by Bosede and Rhoades [18]. The stability of Picard iterative schemes follows as a corollary. The theorem is stated as follows. 
Theorem 3.1 Let $(E,\|\cdot\|)$ be a real normed linear space and $T: E \rightarrow E$ be a map with a fixed point $p$ satisfying the condition

$$
\|T x-p\| \leq \delta\|x-p\|
$$

for each $x, y \in E, 0 \leq \delta<1$. For arbitrary $x_{1} \in E$, let $\left\{x_{n}\right\}_{n=0}^{\infty}$ be the Picard-Mann hybrid iterative scheme defined by (1.3). Then the Picard-Mann hybrid iterative scheme is T-stable.

Proof From Theorem 2.1, the sequence $\left\{x_{n}\right\}$, defined by (1.3), converges to $p$.

Let $\left\{z_{n}\right\}_{n=0}^{\infty},\left\{u_{n}\right\}_{n=0}^{\infty}$ be real sequences in $E$.

Let $\epsilon_{n}=\left\|z_{n+1}-T u_{n}\right\|, n=0,1,2, \ldots$, where

$$
\begin{aligned}
& z_{n+1}=T u_{n}, \\
& u_{n}=\left(1-\alpha_{n}\right) z_{n}+\alpha_{n} T z_{n}, \quad n \geq 0
\end{aligned}
$$

and let $\lim _{n \rightarrow \infty} \epsilon_{n}=0$.

Then we shall prove that $\lim _{n \rightarrow \infty} z_{n}=p$ for mappings satisfying condition (3.1).

That is,

$$
\begin{aligned}
\left\|z_{n+1}-p\right\| & \leq\left\|z_{n+1}-T u_{n}\right\|+\left\|T u_{n}-T p\right\| \\
& \leq \epsilon_{n}+\left\|T u_{n}-T p\right\| .
\end{aligned}
$$

Using condition (3.1) we have

$$
\left\|T u_{n}-T p\right\| \leq \delta\left\|u_{n}-p\right\|
$$

Substituting (3.3) in (3.2) we have

$$
\begin{aligned}
\left\|z_{n+1}-p\right\| & \leq \epsilon_{n}+\delta\left\|u_{n}-p\right\|, \\
\left\|u_{n}-p\right\| & =\left\|\left(1-\alpha_{n}\right) z_{n}+\alpha_{n} T z_{n}-\left(1-\alpha_{n}+\alpha_{n}\right) p\right\| \\
& \leq\left(1-\alpha_{n}\right)\left\|z_{n}-p\right\|+\alpha_{n}\left\|T z_{n}-p\right\| \\
& \leq\left[1-(1-\delta) \alpha_{n}\right]\left\|z_{n}-p\right\| .
\end{aligned}
$$

Substituting (3.5) in (3.4), since $0<\alpha<\alpha_{n}$, we have

$$
\left\|z_{n+1}-p\right\| \leq \delta\left[1-(1-\delta) \alpha_{n}\right]\left\|z_{n}-p\right\|+\epsilon_{n} .
$$

Then

$$
\left\|z_{n+1}-p\right\| \leq \delta[1-(1-\delta) \alpha]\left\|z_{n}-p\right\|+\epsilon_{n} .
$$

Using Lemma 1.1 in (3.6) we have

$$
\lim _{n \rightarrow \infty} z_{n}=p
$$


Conversely, let $\lim _{n \rightarrow \infty} z_{n}=p$. We show that $\lim _{n \rightarrow \infty} \epsilon_{n}=0$ as follows:

$$
\begin{aligned}
\epsilon_{n} & =\left\|z_{n+1}-T u_{n}\right\| \\
& \leq\left\|z_{n+1}-p\right\|+\left\|T p-T u_{n}\right\| \\
& \leq\left\|z_{n+1}-p\right\|+\delta\left\|u_{n}-p\right\| .
\end{aligned}
$$

Substituting (3.7) in (3.6) we have

$$
\begin{aligned}
\epsilon_{n} & \leq\left\|z_{n+1}-p\right\|+\delta\left[\left(1-\alpha_{n}\right)\left\|z_{n}-p\right\|+\alpha_{n}\|T z-p\|\right] \\
& \leq\left\|z_{n+1}-p\right\|+\delta\left[1-(1-\delta) \alpha_{n}\right]\left\|z_{n}-p\right\| \\
& \leq\left\|z_{n+1}-p\right\|+\delta[1-(1-a) \alpha]\left\|z_{n}-p\right\| .
\end{aligned}
$$

Since $\lim _{n \rightarrow \infty}\left\|z_{n}-p\right\|=0$, by our assumption

$$
\lim _{n \rightarrow \infty} \epsilon_{n}=0
$$

Therefore the Picard-Mann iterative scheme (1.3) is T-stable.

Theorem 3.1 yields the following corollary.

Corollary 3.2 (Bosede and Rhoades [18]) Let $(E,\|\cdot\|)$ be a real normed linear space and $T: E \rightarrow E$ be a map with a fixed point $p$ satisfying the condition

$$
\|T x-p\| \leq \delta\|x-p\|
$$

for each $x, y \in E, 0 \leq \delta<1$. For arbitrary $x_{1} \in E$, let $\left\{x_{n}\right\}_{n=0}^{\infty}$ be the Picard iterative scheme defined by (1.1) converging to $p$. Then the Picard iterative scheme defined by (1.1) is T-stable.

\section{Competing interests}

The authors declare that they have no competing interests.

\section{Authors' contributions}

Both authors contributed equally to this work. Both authors read and approved the final manuscript.

\section{Author details}

${ }^{1}$ Department of Mathematics, University of Lagos, Akoka, Yaba, Lagos, Nigeria. ${ }^{2}$ Department of Mathematics, Covenant University, Canaanland, KM 10 Idiroko Road, P.M.B. 1023, Ota, Ogun State, Nigeria.

\section{Acknowledgements}

The authors wish to thank the anonymous referees for their suggestions and corrections which led to the improvement of this paper. The second author is grateful to the Covenant University Centre for Research and Development (CUCRID) for supporting his research.

Received: 27 November 2014 Accepted: 21 April 2015 Published online: 06 May 2015

\section{References}

1. Hussain, N, Chugh, R, Kumar, V, Rafiq, A: On the rate of convergence of Kirk-type iterative schemes. J. Appl. Math. 2012, Article ID 526503 (2012)

2. Phuengrattana, W, Suantai, S: On the rate of convergence of Mann, Ishikawa, Noor and SP-iterations for continuous functions on an arbitrary interval. J. Comput. Appl. Math. 235(9), 3006-3014 (2011)

3. Khan, SH: A Picard-Mann hybrid iterative process. Fixed Point Theory Appl. 2013, 69 (2013)

4. Harder, AM, Hicks, TL: A stable iteration procedure for nonexpansive mappings. Math. Jpn. 33, 687-692 (1988)

5. Harder, AM, Hicks, TL: Stability results for fixed point iteration procedures. Math. Jpn. 33, 693-706 (1988) 
6. Harder, AM: Fixed point theory and stability results for fixed point iteration procedures. Ph. D. thesis, University of Missouri-Rolla (1987)

7. Chidume, CE: Strong convergence and stability of Picard iteration sequences for a general class of contractive-type mappings. Fixed Point Theory Appl. 2014, 233 (2014)

8. Rhoades, BE: Fixed point iteration using infinite matrices. Trans. Am. Math. Soc. 196, 161-176 (1974)

9. Mann, WR: Mean value methods in iterations. Proc. Am. Math. Soc. 44, 506-510 (1953)

10. Chugh, R, Kumar, V: Strong convergence of SP iterative scheme for quasi-contractive operators. Int. J. Comput. Appl. 31(5), 21-27 (2011)

11. Rhoades, BE, Soltuz, SM: The equivalence between Mann-Ishikawa iterations and multi-step iteration. Nonlinear Anal. 58, 219-228 (2004)

12. Akewe, H, Okeke, GA, Olayiwola, A: Strong convergence and stability of Kirk-multistep-type iterative schemes for contractive-type operators. Fixed Point Theory Appl. 2014, 45 (2014)

13. Ishikawa, S: Fixed points by a new iteration method. Proc. Am. Math. Soc. 44, 147-150 (1974)

14. Berinde, V: Iterative Approximation of Fixed Points. Editura Efemeride, Baia Mare (2002)

15. Osilike, MO: Stability results for Ishikawa fixed point iteration procedure. Indian J. Pure Appl. Math. 26(10), 937-941 (1995)

16. Rhoades, BE: Fixed point theorems and stability results for fixed point iteration procedures. Indian J. Pure Appl. Math. 21, 1-9 (1990)

17. Imoru, CO, Olatinwo, MO: On the stability of Picard and Mann iteration. Carpath. J. Math. 19, 155-160 (2003)

18. Bosede, AO, Rhoades, BE: Stability of Picard and Mann iteration for a general class of functions. J. Adv. Math. Stud. 3(2), 1-3 (2010)

19. Chidume, CE, Olaleru, JO: Picard iteration process for a general class of contractive mappings. J. Niger. Math. Soc. 33 19-23 (2014)

20. Bosede, AO: Noor iterations associated with Zamfirescu mappings in uniformly convex Banach spaces. Fasc. Math. 42 29-38 (2009)

21. Rhoades, BE: A comparison of various definition of contractive mapping. Trans. Am. Math. Soc. 226, 257-290 (1977)

22. Zamfirescu, T: Fixed point theorems in metric spaces. Arch. Math. (Basel) 23, 292-298 (1972)

23. Berinde, V: On the stability of some fixed point procedures. Bul. Ştiinţ. - Univ. Baia Mare, Ser. B Fasc. Mat.-Inform. 18(1), 7-14 (2002)

\section{Submit your manuscript to a SpringerOpen ${ }^{\circ}$ journal and benefit from:}

- Convenient online submission

- Rigorous peer review

- Immediate publication on acceptance

- Open access: articles freely available online

- High visibility within the field

Retaining the copyright to your article 